\title{
Analysis of post-blasting source mechanisms of mining- induced seismic events in Rudna copper mine, Poland
}

\author{
Alicja Caputa ${ }^{1}$, Adam Talaga ${ }^{2}$, Łukasz Rudziński $^{3}$ \\ ${ }^{1}$ Department of Applied Geology, Faculty of Earth Sciences, University of Silesia, 60 Bedzinska Str, 41-200 \\ Sosnowiec, Poland; \\ corresponding author: ala.caputa@gmail.com \\ ${ }^{2}$ KGHM Polska Miedź S.A., 48 M. Skłodowskiej-Curie Str., 59-301 Lubin, Poland; a.talaga@kghm.pl \\ ${ }^{3}$ Institute of Geophysics PAS, Department of Seismology, Ksiecia Janusza 64 str. 01 - 452 Warszawa, Poland; \\ rudzin@igf.edu.pl,
}

Received: $28^{\text {th }}$ May, 2015

Accepted: $11^{\text {th }}$ November, 2015

\begin{abstract}
The exploitation of georesources by underground mining can be responsible for seismic activity in areas considered aseismic. Since strong seismic events are connected with rockburst hazard, it is a continuous requirement to reduce seismic risk. One of the most effective methods to do so is blasting in potentially hazardous mining panels. In this way, small to moderate tremors are provoked and stress accumulation is substantially reduced. In this paper we present an analysis of post-blasting events using Full Moment Tensor (MT) inversion at the Rudna mine, Poland, underground seismic network. In addition, we describe the problems we faced when analyzing seismic signals. Our studies show that focal mechanisms for events that occurred after blasts exhibit common features in the MT solution. The strong isotropic and small Double Couple (DC) component of the MT, indicate that these events were provoked by detonations. On the other hand, post-blasting MT is considerably different than the MT obtained for strong mining events. We believe that seismological analysis of provoked and unprovoked events can be a very useful tool in confirming the effectiveness of blasting in seismic hazard reduction in mining areas.
\end{abstract}

Key words: source mechanism, blasting, foci

\section{Introduction}

Underground exploitation of copper ore in deep copper mines in the Lower Silesian Copper District, Poland (LSCD) is associated with many mining hazards. In Polish copper mines undoubtedly the most significant danger is high seismic activity. The strongest mining tremors can be considered as small earthquakes associated with rockburst, and this is a continuous problem during exploitation. The rockburst hazard is caused by high-energy tremors induced by mining operations. Historically, the first significant mininginduced event (M 2.8) occurred on 31 July 1972 at the Lubin Mine, one of the three deep copper mines located in the LSCD. Since that time, the continued progress of ore extraction has produced a regular increase in the number and strength of recorded events (Butra, 2011). Large high-energy seismic events, $\left(\mathrm{E}>10^{5} \mathrm{~J} ; 11,200\right.$ events during 1990-2010), with the cumulative energy of 70,48 GJ and 323 events between 1990 and 2010 (Butra, 2011), indicate that the seismic hazard in Lower Silesian copper mines cannot be ignored. To decrease such hazardous situations, mining management utilize several preventative measures, including technical, active and organizational methods. The most effective approach is by utilizing a group of 
active methods, consisting of provoking tremors by the detonation of an explosive charge in the blast holes. This is especially important in mining panels with a considerably high level of rockburst hazard.

Since mining extraction based on both room-and-pillars and longwall methods can produce seismic activity by changes in the local stress field (Gibowicz and Kijko, 1994), active prevention with properly designed blasting can be a very effective method to reduce the risk for miners and underground infrastructure. In this paper, using focal mechanisms analysis based on Full Moment Tensor (MT) inversion, we show that blasting is readily utilized to produce controlled seismic events. Moreover, events after blasts are characterized by a quite strong MT isotropic component, which contradicts MT obtained for strong seismic events recorded by Rudna's mine seismic network.

\section{Characterization of the Lower Silesian Copper District}

The Lower Silesian Copper District is located in SW Poland. Currently, the district is one of the most important mining areas in Europe, producing 30.2 million tons of copper ore per year (www.kghm.pl). In this area, three underground mines (Fig. 1), "Lubin", "Polkowice-Sieroszowice" and "Rudna", are in operation (Butra, 2010). Rich copper deposits were discovered at the end of the 1950s, and ore exploitation started in 1967 at the Lubin mine. The stratoidal type copper deposit on the Foresudetic Monocline is characterized by a small inclination (approximately $4^{\circ}$ ), variable thickness (from 0.4 to $26 \mathrm{~m}$ ), and a varying lithological profile - sandstones, dolomites and ore shales can be found at depths between 600 $\mathrm{m}$ and $1400 \mathrm{~m}$ below the surface.

The analysis presented in this paper is based on data recorded from the Rudna mine underground seismic network. The network consists of 32 vertical Willmore II and III seismometers (1-100 Hz). Signals are recorded with a sampling rate of $500 \mathrm{~Hz}$ and dynamic range of less than $66 \mathrm{~dB}$ (Koziarz and Szłapka 2008). The mine operates at depths of $950 \mathrm{~m}$ to $1150 \mathrm{~m}$ with a room and pillar (pillar and stall) exploitation system. The copper ore is excavated with rooms (bored by explosives) located perpendicularly to the exploitation front line and stripes located parallel, leaving pillars supporting the roof over excavated areas (Lizurek et al., 2015). To extract the output, the detonation of explosive charges is used in all Polish copper mines.

\section{Determination of the focal mechanism of mining tremors}

The focal mechanism of mining seismic events, such as for natural earthquakes, can be described by certain systems of couples forces that act on a particular piece of rock medium. As a result of this action, a tremor focus is initiated (Dubiński, 2013). The main goal of determining the focal mechanism is to define the force distribution in the source, which leads to the movement of the elastic energy emission and finally, to seismic wave propagation. Assuming that the source can be described by a pure Double Couple (DC), the mechanism of the seismic event can be considered as spatial orientations of two, perpendicular nodal planes, separating the two areas of compression and dilatation inside the source. While one of these planes is the actual focal plane on which the movement took place and the emission wave started, the second is considered as an auxiliary plane (Dubiński, 2013) (Fig. 2). The spatial location of these planes is described by three angles $\varphi($ strike), $\delta$ (dip), $\lambda$ (slip angle).

Focal mechanism analysis in Polish mining seismology has been carried out since the beginning of the 1990s (Wiejacz 1991, Gibowicz \& Kijko, 1994) and nowadays is one of the most important methods employed to investigate and understand mining induced seismicity. 


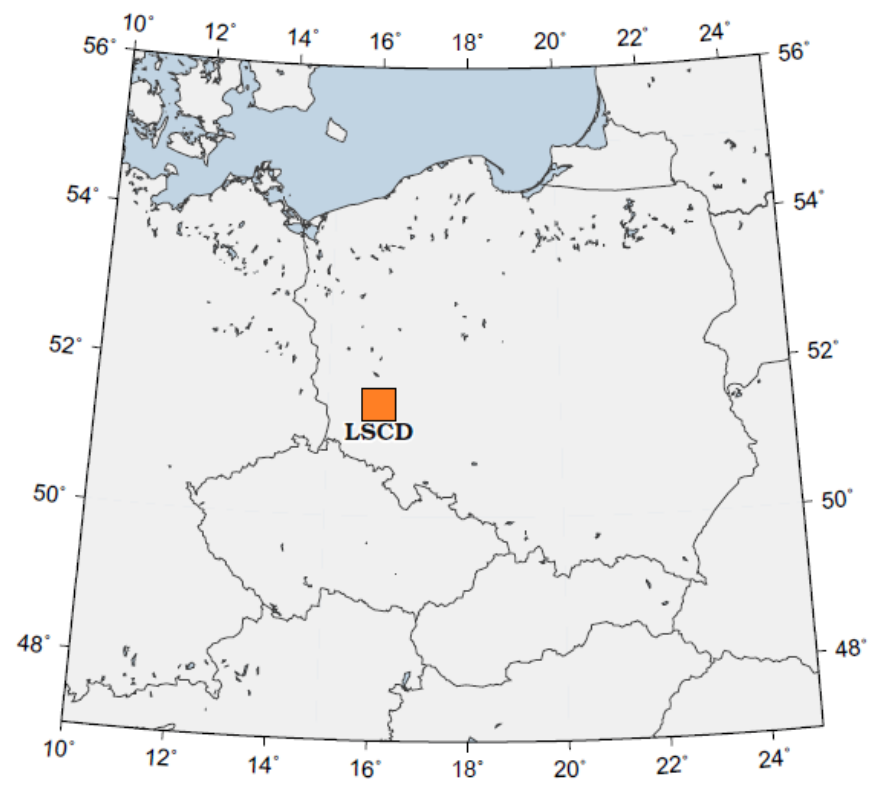

Fig.1. Location of LSCD with three deep copper mines: Lubin, Polkowice - Sieroszowice and Rudna.
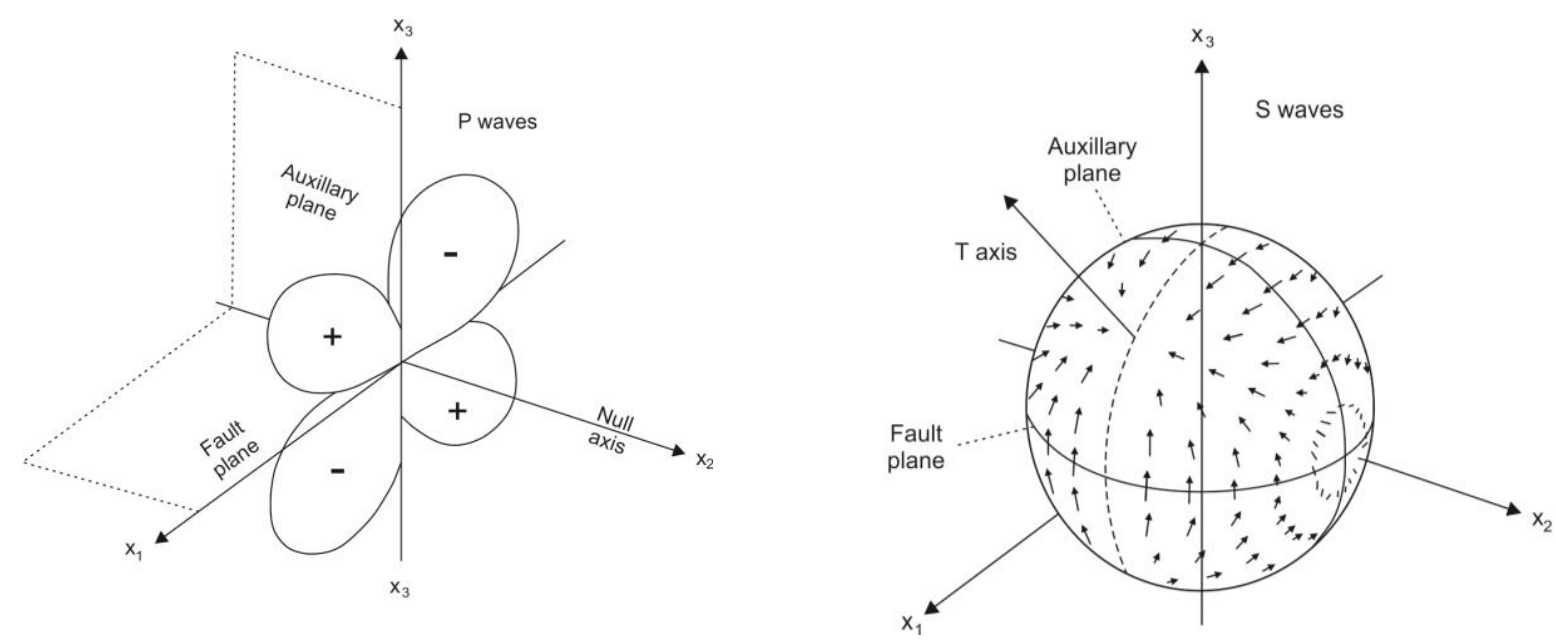

Fig.2. The P- wave radiation pattern for a double couple source (Stein \& Wysession, 2003)

Since that time, based on digital seismograms, a MT inversion rather than a pure DC solution, is a more appropriate way to estimate the source mechanism of mining events in Polish mines. This method is based on seismogram analyses and assumes that the displacement recorded in the far field $\left(u_{k}\right)$ is caused by a system of forces acting on the focus, and is the sum of the displacements caused by the particular force couples (Aki \& Richards 1980). This movement can be described by the equation:

$$
u_{k}=\frac{M_{i j} * \partial G_{k i}}{\partial x_{j}}=M_{i j} * G_{k i, j}
$$

where $\mathrm{M}_{\mathrm{ij}}$ (Full Moment Tensor) describes the moment of the force couples acting in the direction of the $x_{i}$ axis of the arm in line with the $x_{j}$ axis; $G_{i j}$ (Green's function), describes the impulse response of the medium for the distance traveled by the seismic wave; $*$ - convolution operation.

The MT fully describes the system of forces that are acting in the seismic source, which must be assumed to have a point nature. This 
assumption is fulfilled as the distances between the hypocenter and receivers are much longer than the size of the source. The MT as a physical factor is a linear combination of force couples and the moments. Another assumption in this method is that all of the seismic moment tensor components depend on time in the same way, meaning there is a synchronous source generating the same changes in time in all directions (Stec, 2009). Applying these two statements, the displacement field equation (1) can be written as:

$u_{k}(x, t)=M_{i j}\left[G_{k i, j} * s(t)\right]$

where $s(t)$, the Source Time Function (STF), characterizes changes of a seismic source in time.

As follows from equation (2) the displacement field $u_{k}$ is a linear function of the components of the seismic moment tensor and the terms in square brackets. With the assumption that STF is described by the Dirac delta (Stec, 2009), the displacement field $u_{k}$ can be written as:

$u_{k}=M_{i j} G_{k i, j}$

The $\mathrm{MT}\left(\mathrm{M}_{\mathrm{ij}}\right.$ in equation above) can be presented as a nine-component matrix $\mathrm{M}$ with dimensions of $3 \times 3$ :

$M=\left[\begin{array}{lll}M_{11} & M_{12} & M_{13} \\ M_{21} & M_{22} & M_{23} \\ M_{31} & M_{32} & M_{33}\end{array}\right]$

The moment tensor provides a general representation of the internally generated forces that can act at a point in an elastic medium. The rule that angular momentum has to be conserved requires that $\mathrm{M}$ is a symmetric tensor and has only six independent elements (Shearer, 2009). Every component of the MT matrix represents another pair of forces acting in the source of the event (Fig. 3).
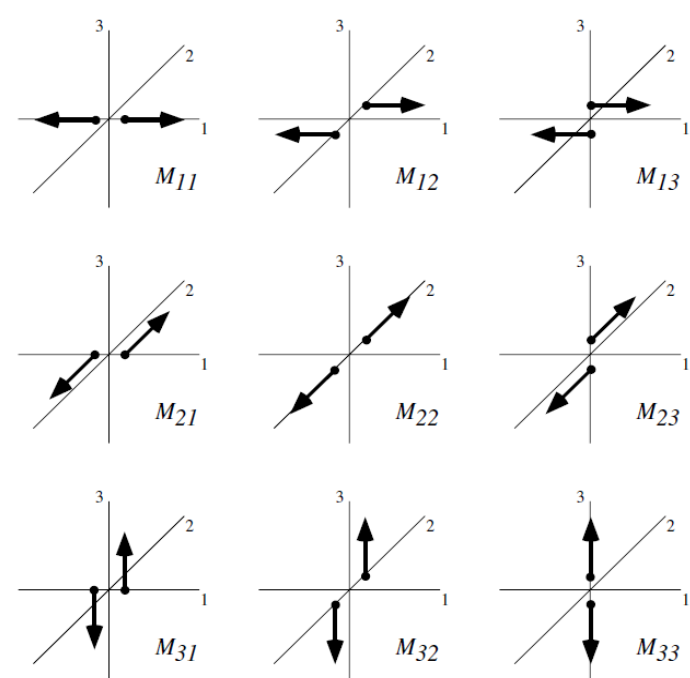

Fig.3. The nine different force couples that make up the components of the moment tensor. (Aki \& Richards, 1980)

Such a defined MT can be further decomposed in other ways. The most acceptable in mining seismology is decomposition into the isotropic component $\left(\mathrm{M}^{0}\right)$ and the deviatoric component (M'), which is written as follows (Jost and Hermann, 1989):

$M=M^{0}+M^{\prime}$

In $\mathrm{M}^{0}$, the diagonal components (where $i=j$ ) describe the force couples within the moment, which are directed along the main axis. They are responsible for the volume changes in the tremor source and are the evidence of the explosion (when the value is positive $/+/$ ) or of the implosion (if the value is negative/-/).

The deviatoric component of MT (M') can be further decomposed, although with some inaccuracy, into a Compensated Linear Vector Dipole (CLVD) (corresponding to uniaxial compression (/-/) or tension $(/+/)$ and double force couples (DC) (indicating a pure shear motion in the event source, i.e. on the fault plane). Decomposition of the deviatoric component can be written as: 
$M^{\prime}=M^{D C}+M^{C L V D}$

Therefore, the full decomposition of the MT (Fig. 4) is defined as:

$M=M^{0}+M^{C L V D}+M^{D C}$

The procedure to find the MT (Moment Tenor Inversion) is based on seismic signals recorded at several seismic stations, surrounding the source. Since MT has 6 independent elements, at least seven signals should be available. Utilizing the correct procedure the inversion is optimized, i.e. the minimization of the variation between synthetics and observations in a chosen norm (Gibowicz and Kijko 1994).

Therefore, based on seismogram analysis and further on the decomposition of the seismic moment tensor, we can estimate a point source mechanism of the seismic event. The interpretation of the explosive or implosive point source model (i.e. high isotropic component) corresponds to the process of the volume changes within the rock mass. One of the reasons for this could be shooting (blast) at the selected layer of the deposit or in its close vicinity. Another reason could be rock destruction by the pressure of a large overlying rock mass. The CLVD indicates uniaxial compression or tension and may involve the destruction of pillars. Finally, the model represents the mechanism described by a DC component corresponding with events associated with the cracking of thick and dense strata with a high degree of stiffness and strength, or the movement of their fragments. Commonly, it refers to undermined complexes of roof rocks. The DC component is generally highest in the case of natural and strong events and is more relevant when describing tectonic earthquakes. Since, in case of mining seismology, the strong non-DC components play a significant role, we are interested in the full MT rather than just the DC solution.

\section{The Rudna Mine case study}

\section{Site and data description}

All events used in our analysis occurred on the G-11/8 mining panel (Fig. 5) between January 2012 and November 2014. During this time more than 15,000 induced seismic events were recorded but only 135 were strong enough $\left(\mathrm{E}>10^{5} \mathrm{~J}\right)$ to for MT analysis.

A cluster of post-blasting events comprised of tremors took place at the moment of explosive charge detonation (classified as event 0 seconds after blasting by Rudna Geophysical Mining Survey), and immediately after blasting (21 seconds after detonation). The second part of this group was created by two tremors during the post-blast waiting time, respectively in 5 minutes and 4 hours and 7 minutes after blasting.

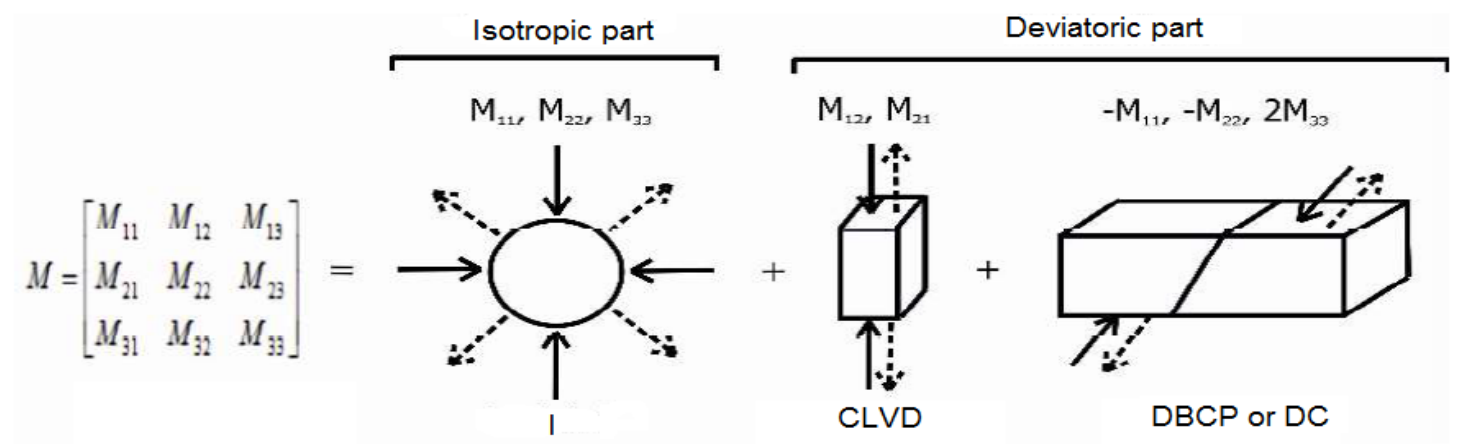

Fig.4. Graphic interpretation of the seismic moment tensor inversion (after Talaga, 2014) 


\section{G11/8.}

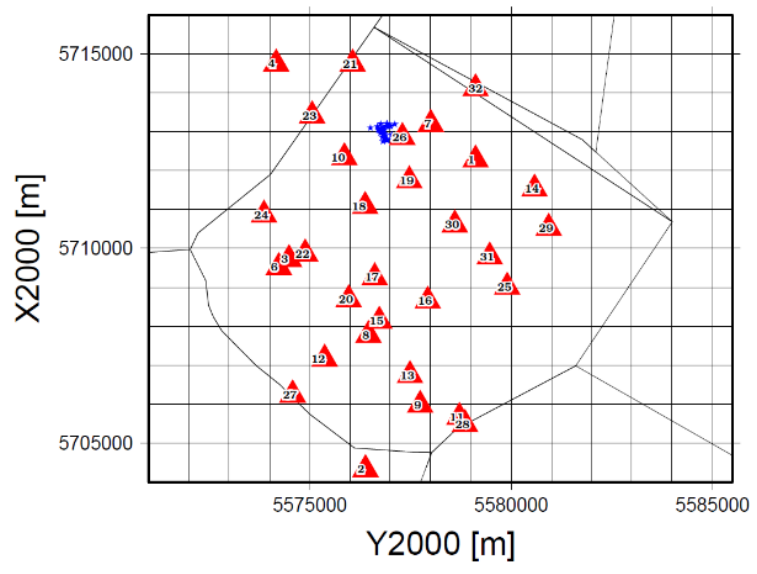

Fig.5. Epicenters (blue stars) mark the localization of analyzed events within mining panel G-11/8 at Rudna copper mine. The seismic network is represented by red triangles

From this group we selected 4 events, which occurred just after blasting and compared their mechanisms with the strong, mining-induced seismic tremors that occurred on the same panel in the vicinity of the selected cluster.

MT inversion: $P$ - wave amplitude

All analyses and calculations during this study were performed using FOCI software (Kwiatek, 2013), with the MT inversion in the time domain from amplitudes of P-wave onset recorded by the underground seismic network at Rudna Mine (Fig. 5). The velocity model of the Rudna mine assumes that the recorded first onsets maybe of different types (Król 1998): direct P-waves, which are observed on seismograms recorded closer than $1 \mathrm{~km}$ from the hypocenter, and two refracted waves. The refracted P-waves in LSCD's conditions are divided into refractive wave $A$ and refractive wave $\mathrm{B}$. The A-wave is defined as a seismic wave refracted from the deposit overlying an anhydrite layer (Lizurek et al., 2015) and is recorded between $1 \mathrm{~km}$ to approximately $2.8 \mathrm{~km}$ from the hypocenter. The B-wave is a wave refracted from the thick strata of sandstone underlying the shale layer (Lizurek et al., 2015) and is recorded by seismometers located at a distance of more than $2.8 \mathrm{~km}$ from the source. The velocities of wave propagation were specified based on seismological observations: $5 \mathrm{~km} / \mathrm{s}$ for the direct wave, 5.9 $\mathrm{km} / \mathrm{s}$ for the refracted A-wave, and $5.6 \mathrm{~km} / \mathrm{s}$ for the refracted B-wave (Król, 1998).

In the present study all types of waves were used, with 32 onsets at 32 stations located in the Rudna mine area. The input parameters are the amplitude and polarity information on the first P-wave displacement pulses. According to Fitch et al. (1980), the recorded displacement for the vertical component of the P-wave phase is (Lizurek et al., 2015):

$\mathrm{u}_{\mathrm{z}}^{\mathrm{P}}(\mathrm{x}, \mathrm{t})=\frac{1}{4 \pi \rho \alpha^{3} \mathrm{r}}\left[\bar{\gamma} \mathrm{Ms}\left(\mathrm{t}-\frac{\mathrm{r}}{\alpha}\right) \bar{\gamma}\right] \mathrm{l}_{\mathrm{z}}$

where $\rho$ is the average density, $r$ is the sourcereceiver distance, $\alpha$ is the average velocity of $\mathrm{P}$ wave, $M$ is the seismic moment, $l_{z}$ is the cosine of the angle of the incidence, and $\gamma$ is the takeoff angle, $s$ is the STF.

Such a procedure is part of the FOCI software and allows for the calculation of the full MT as well as pure DC solution.

During this analysis we used the full moment tensor inversion using L2 norm. The MT was decomposed into the isotropic component (volume change), CLVD (linear compression/dilatation) and DC (shear motion). The former, namely the volume change component of the solution, is key for this work as it can show that there was an increase of volume in the source, and can be treated as an indicator that a blasting mechanism was the reason for the event. In general we expect, in this case, that the DC component after the explosion is low.

The principal problems of determining source mechanism

All geophysical analyses are exposed to measurement errors and many factors that 
reduce the quality of results should be taken into account. The principal issues in determining the source mechanism of induced tremors using FOCI software were:

- large errors of the Z (depth) coordinate estimation - since FOCI provides tremor depth tests, in many cases it was necessary to change and correct the depth of the hypocenter based on the MT error (Fig. 6);

- in the case of small events, low wave amplitudes cause difficulties in sorting first arrivals (Fig. 7);
- saturated records and consequently clipped signals from the high energetic seismic event (Fig. 8);

- resonance signal (Fig. 9) - no information of P-wave arrivals.

- electrical disturbances (Fig. 10)

- no signal in selected channels

- filter artifacts, which could be apparently treated as a P-wave onset (Fig 11);

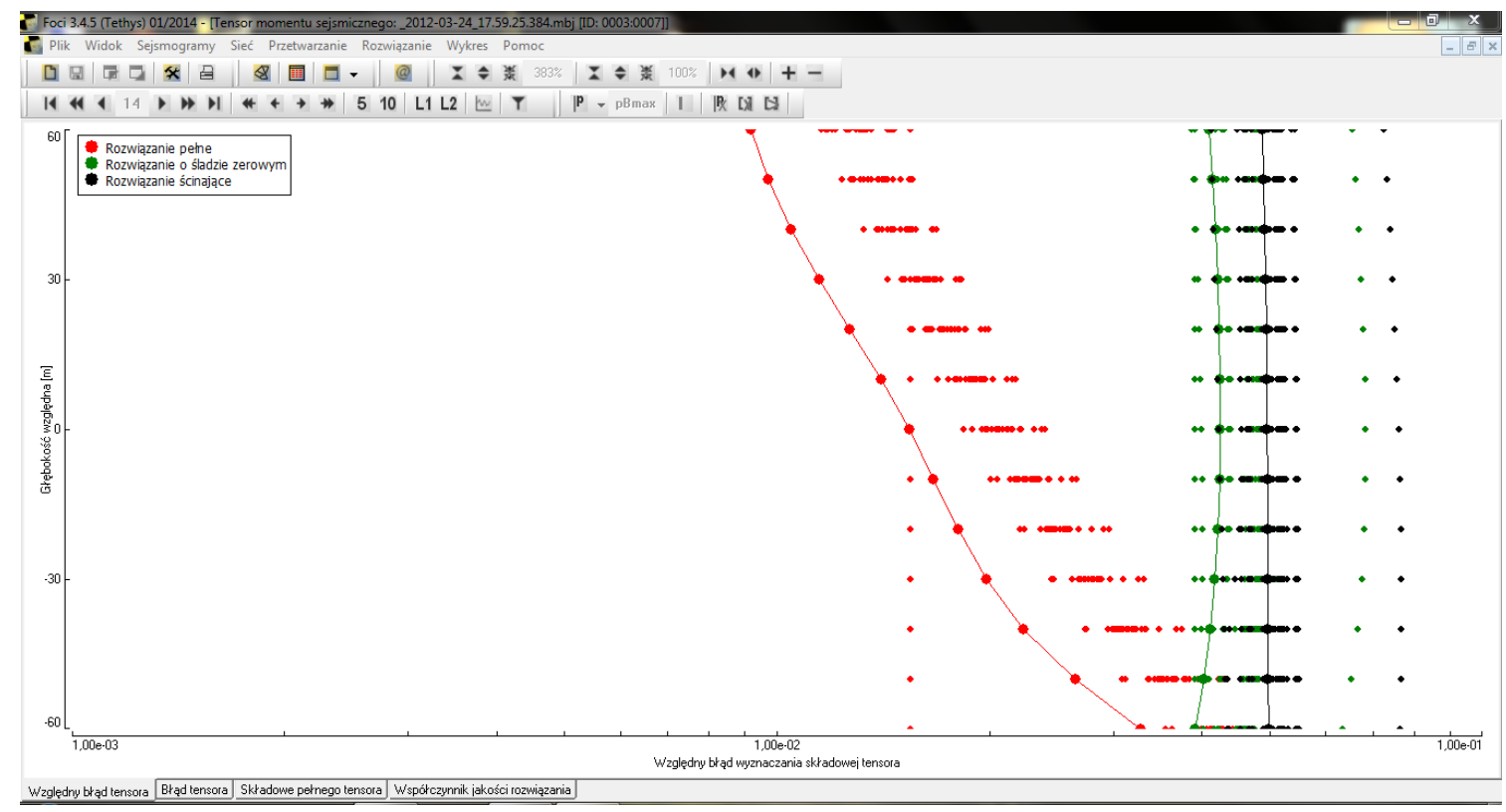

Fig.6. The sample chart of tensor error generated in FOCI software during depths test.

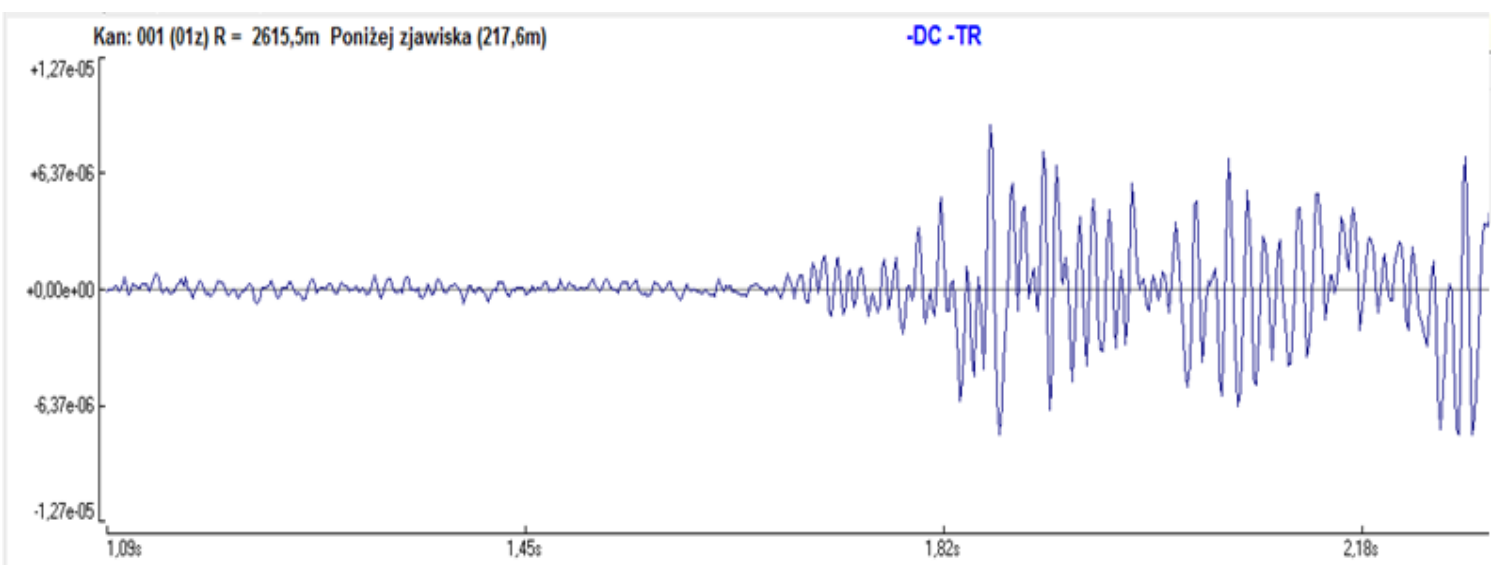

Fig.7. Low amplitudes of P-wave first arrival presented on a seismogram for small event $\left(\mathrm{E}=1 * 10^{5} \mathrm{~J}\right)$ recorded at a station $2.6 \mathrm{~km}$ away from the hypocenter. 


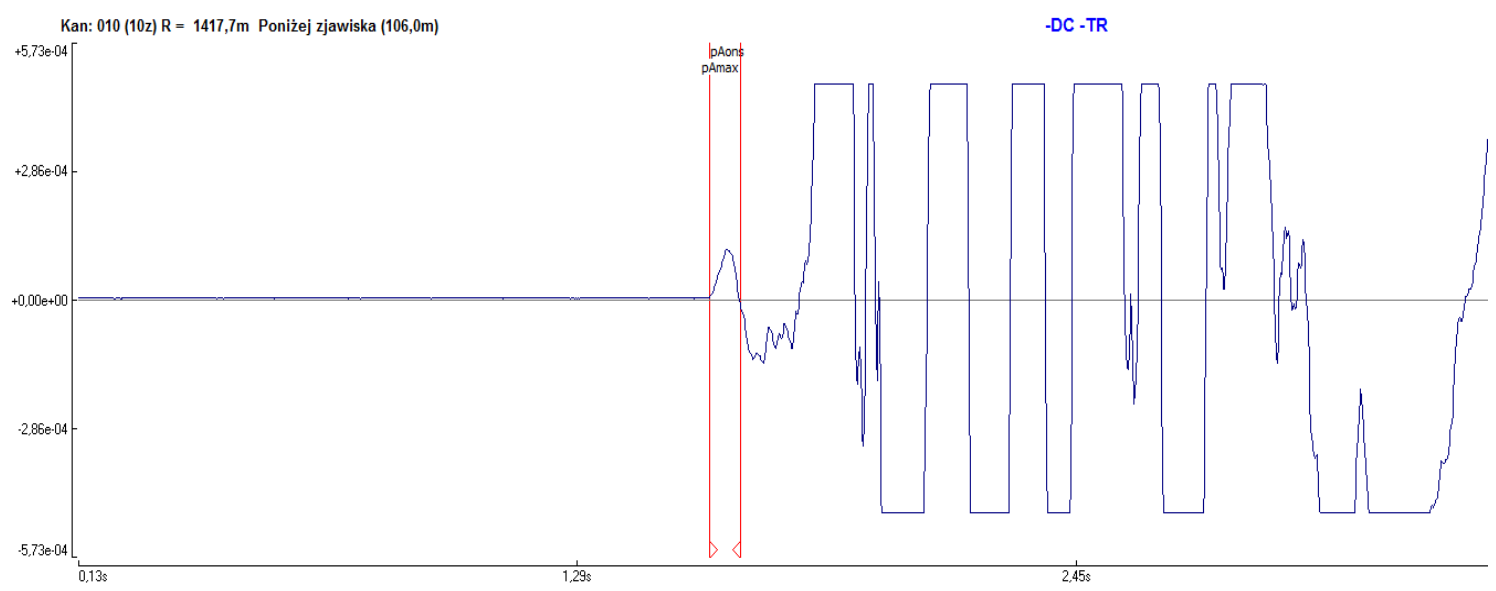

Fig.8. Clipped signal presented as a seismogram $1.4 \mathrm{~km}$ away from hypocenter.

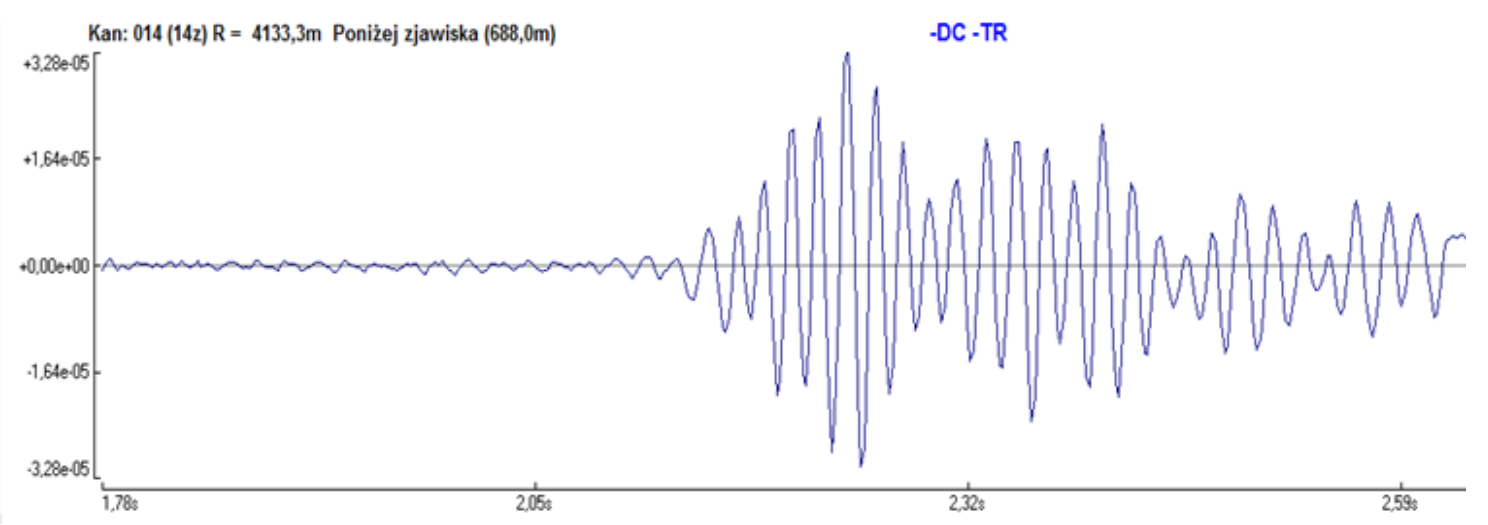

Fig.9. Resonance signal presented as a seismogram

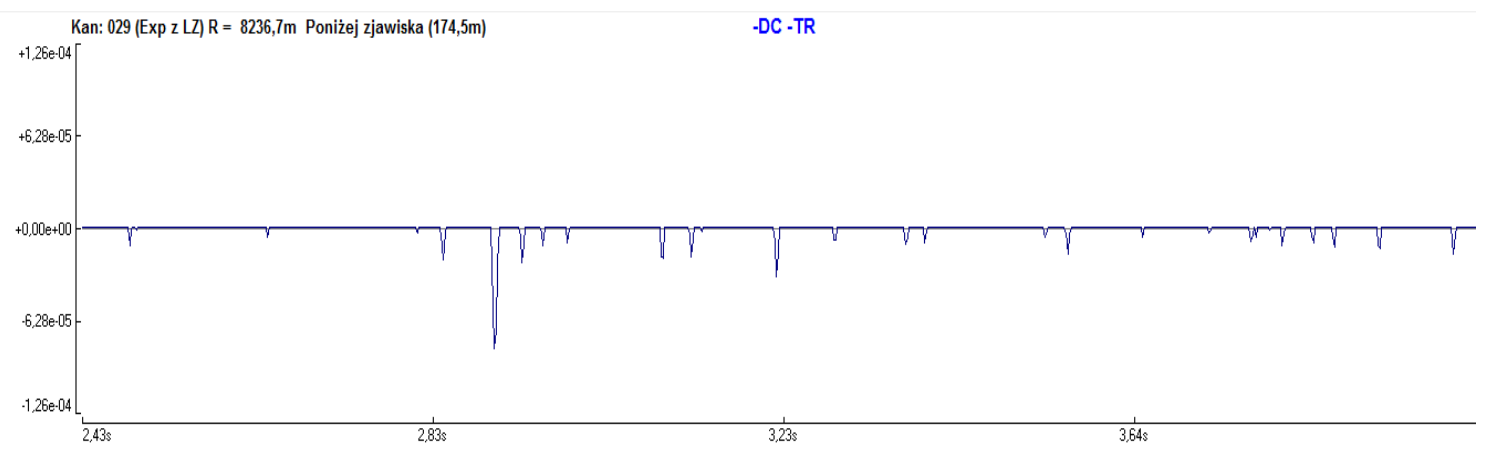

Fig.10. Electrical disturbances presented as a seismogram 


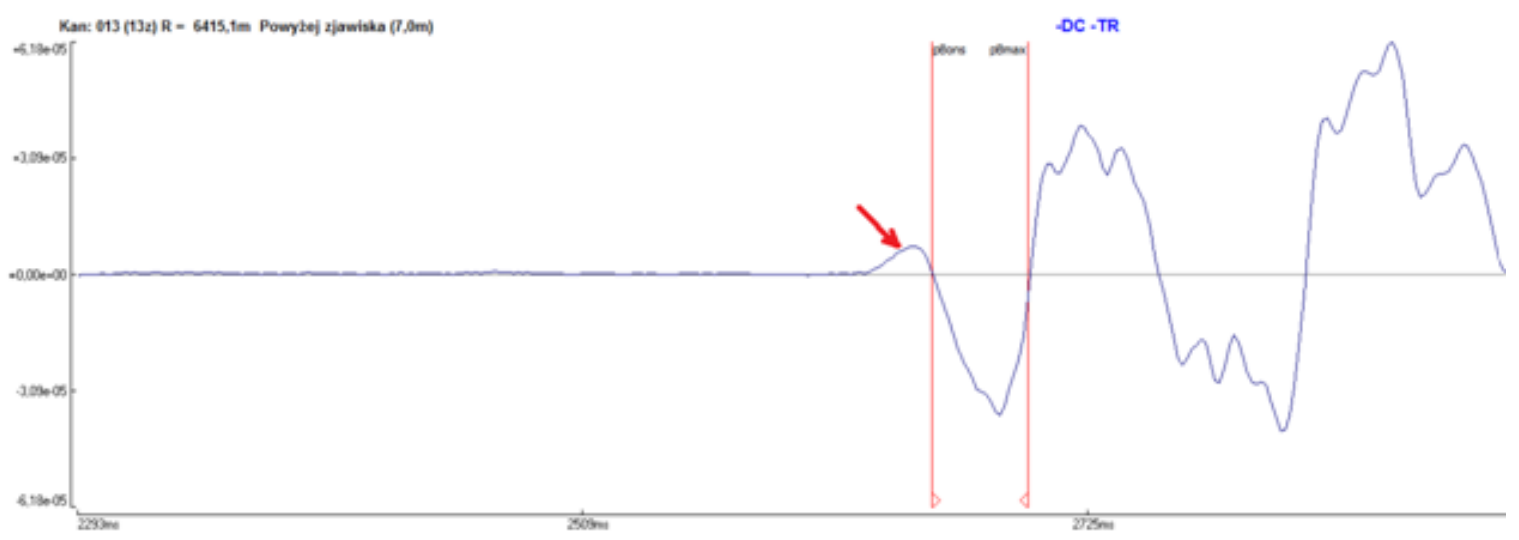

Fig.11. P-wave onset marking and filter artifact (red arrow) presented as a seismogram

\section{Results of source mechanism calculations for selected tremors}

In Table 1 presents the MT for the event occurring at the time of detonation. There was group winning blasting combined with release blasting in the roof of the mining level. For this operation $3582 \mathrm{~kg}$ in total of explosive charge was used (1726 kg rock solid, plus $1856 \mathrm{~kg}$ in roof). The most characteristic issue is a high percentage of explosive components showing volume changes in a source. When the value is positive it can be considered as compression due to blasting in the source. In this case, the highest value of the decomposed elements is found in the linear dilatation (CLVD) and is equal to almost $60 \%$. Linear extension (L1) in the foci is influenced by an explosion at the source. Taking into account that the highest effects of the event occurred in the roof of the deposit level, the extension may be explained by the redistribution of stress near the excavation area. Finally, the small DC component of the MT indicates, that shearing motion on nodal planes can be negligible. This statement is in agreement with our expectation that seismic events controlled by blasting exhibit strong non-DC focal mechanisms.

Similar results and explanations are also seen for the next two examples of post-blasting events. In the case of the second example (Table 2) tremors were induced by group winning blasting, where $2131 \mathrm{~kg}$ of explosive charge was fired.

Tab.1. Source mechanism (full MT and decomposition) of tremor in $0 \mathrm{~s}$ after blasting.

\begin{tabular}{|c|c|c|}
\hline \multicolumn{3}{|c|}{ TREMOR 0 S AFTER DETONATION } \\
\hline ENERGY & & $10^{5} \mathrm{~J}$ \\
\hline \multicolumn{3}{|c|}{${ }_{t}^{+}$} \\
\hline \multicolumn{3}{|c|}{ FULL MOMENT TENSOR SOLUTION } \\
\hline $\begin{array}{c}\mathrm{M}_{11}= \\
+2.02 \mathrm{E}+09 \\
{[\mathrm{Nm}]}\end{array}$ & $\begin{array}{c}\mathrm{M}_{12}= \\
+1.95 \mathrm{E}+11 \\
{[\mathrm{Nm}]}\end{array}$ & $\begin{array}{c}\mathrm{M}_{13}= \\
+3.99 \mathrm{E}+11 \\
{[\mathrm{Nm}]}\end{array}$ \\
\hline$M_{21}=$ & $M_{22}=$ & $M_{23}=$ \\
\hline $\begin{array}{c}+1.95 \mathrm{E}+11 \\
{[\mathrm{Nm}]}\end{array}$ & $\begin{array}{c}+5.91 \mathrm{E}+10 \\
{[\mathrm{Nm}]}\end{array}$ & $\begin{array}{c}+2.27 \mathrm{E}+11 \\
{[\mathrm{Nm}]}\end{array}$ \\
\hline$M_{31}=$ & $M_{32}=$ & $M_{33}=$ \\
\hline $\begin{array}{c}+3.99 \mathrm{E}+11 \\
{[\mathrm{Nm}]}\end{array}$ & $\begin{array}{c}+2.27 \mathrm{E}+11 \\
{[\mathrm{Nm}]}\end{array}$ & $\begin{array}{c}+3.45 \mathrm{E}+12 \\
{[\mathrm{Nm}]}\end{array}$ \\
\hline \multicolumn{3}{|c|}{ COMPONENTS } \\
\hline EXPL & CLVD & DBCP \\
\hline $33.3 \%$ & $56.9 \%$ & \multirow{2}{*}{$\begin{array}{l}\mathbf{9 . 8} \% \\
\text { ERR }\end{array}$} \\
\hline \multicolumn{2}{|l|}{$Q$} & \\
\hline \multicolumn{2}{|l|}{$70 \%$} & $E+10[\mathrm{Nm}]$ \\
\hline
\end{tabular}


Tab.2. Source mechanism of tremor in $21 \mathrm{~s}$ after blasting.

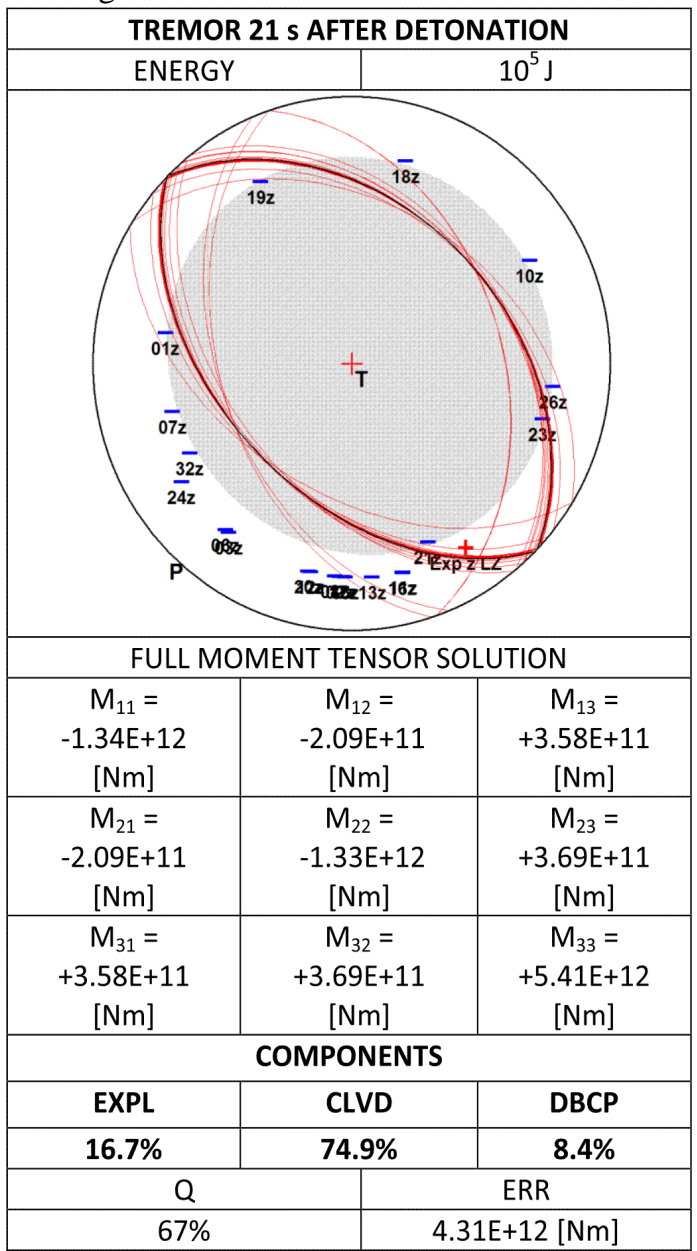

A smaller isotropic component than in first case can be directly connected to a longer time interval between the blast and the origin time of the event. Nevertheless, both high CLVD and very small DC partially support idea that this event was provoked by detonations, although was not observed during blasting. The analyzed event in Table 3 pertains to the post-blast waiting-time tremor (i.e. occurred at the time when seismic events are expected). This event was controlled by a group winning blasting, where $2136 \mathrm{~kg}$ of explosive charge was detonated. Components of the MT in this case are quite similar to the two previous solutions. The isotropic component is still quite high and its positive value indicates an increase in volume in the source. As in previous results linear extension has the highest value. The DC value is the only contrast. In this case the DC component presents the higher value of the full moment tensor solution. This can be explained by a larger share of shear motion in the source due to the partial relaxation of the post blasting pressure, and the release of cumulated energy on the fault plane. characterized by the highest DC component of all previously analyzed examples.

Tab.3. Source mechanism of tremor in 5 min after blasting

\begin{tabular}{|c|c|c|}
\hline \multicolumn{3}{|c|}{ TREMOR 5 min AFTER DETONATION } \\
\hline \multicolumn{3}{|c|}{ ENERGY } \\
\hline \multicolumn{3}{|c|}{} \\
\hline
\end{tabular}

Group winning blasting, utilizing $2103 \mathrm{~kg}$ of explosive charge, provoked the source mechanism of post-blasting tremors, presented in Table 4. This MT solution is characterized by the highest DC component of all previously analyzed examples. The seismic moment tensor decomposition indicates that there was a more significant share of shear motion $(32 \%)$ and 
linear extension (48\%) at the event source. This DC component value and the much higher energy $\left(10^{6} \mathrm{~J}\right)$ of the tremor could be an indicator of the elastic rebound of the rock mass. Nevertheless, a relatively high positive value for the isotropic component suggests an explosive origin for this event. Although this particular event occurred more than four hours after detonation, it was still during the post-blast waiting time. Full MT solution for this event also supports idea that blasting successfully provoked it.

Tab.4. Source mechanism of tremor in $4 \mathrm{~h} 7 \mathrm{~min}$ after blasting

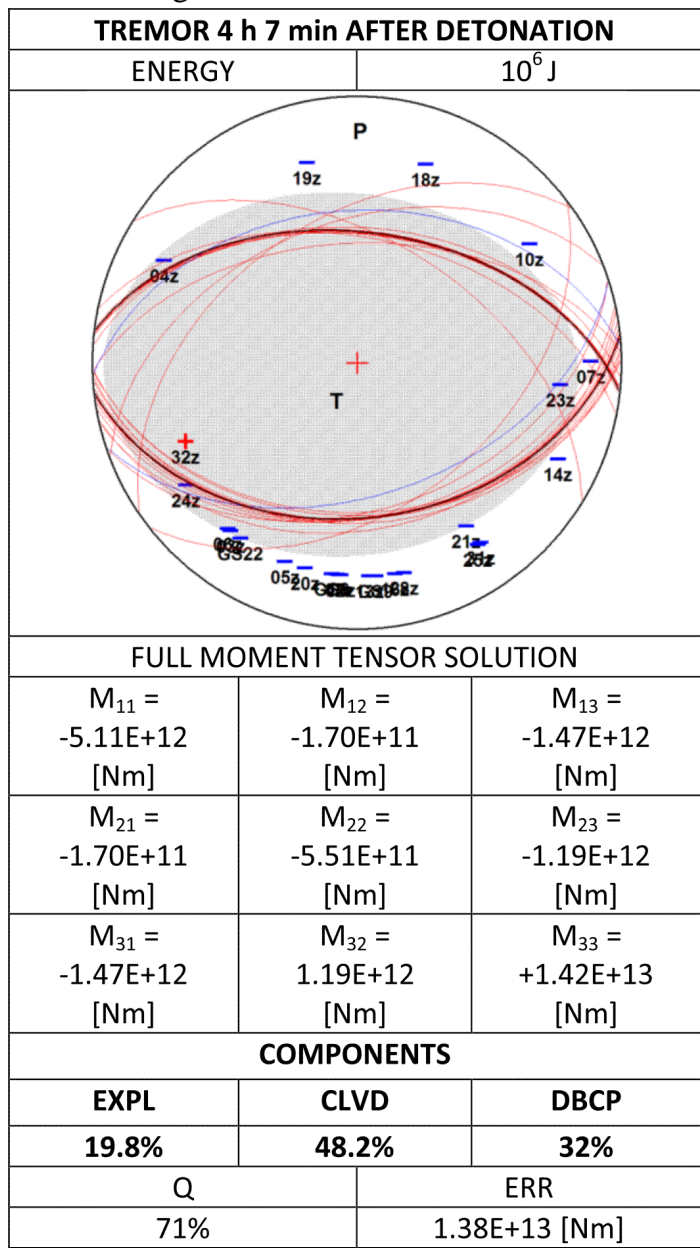

The final seismic event analyzed was the strongest, and occurred in the panel G-11/8 during the period of observation 2012-2014. The event was classified as natural (i.e. did not occur during waiting time after blasting). The full MT for this example is presented in Table 5. There are visible differences between this focal mechanism and the solutions of postblasting tremors. Isotropic components in the last MT solution indicates compression forces in the source, which is completely in contradiction with previous solutions. The value of the compensated linear vector dipole is also evidence of linear compression. Thus, isotropic and CLVD components are related to a compressive stress field close to the excavation level (acting especially in the pillars and undisturbed part of deposit).

Tab.5. Source mechanism of mining induced tremor unrelated with blasting

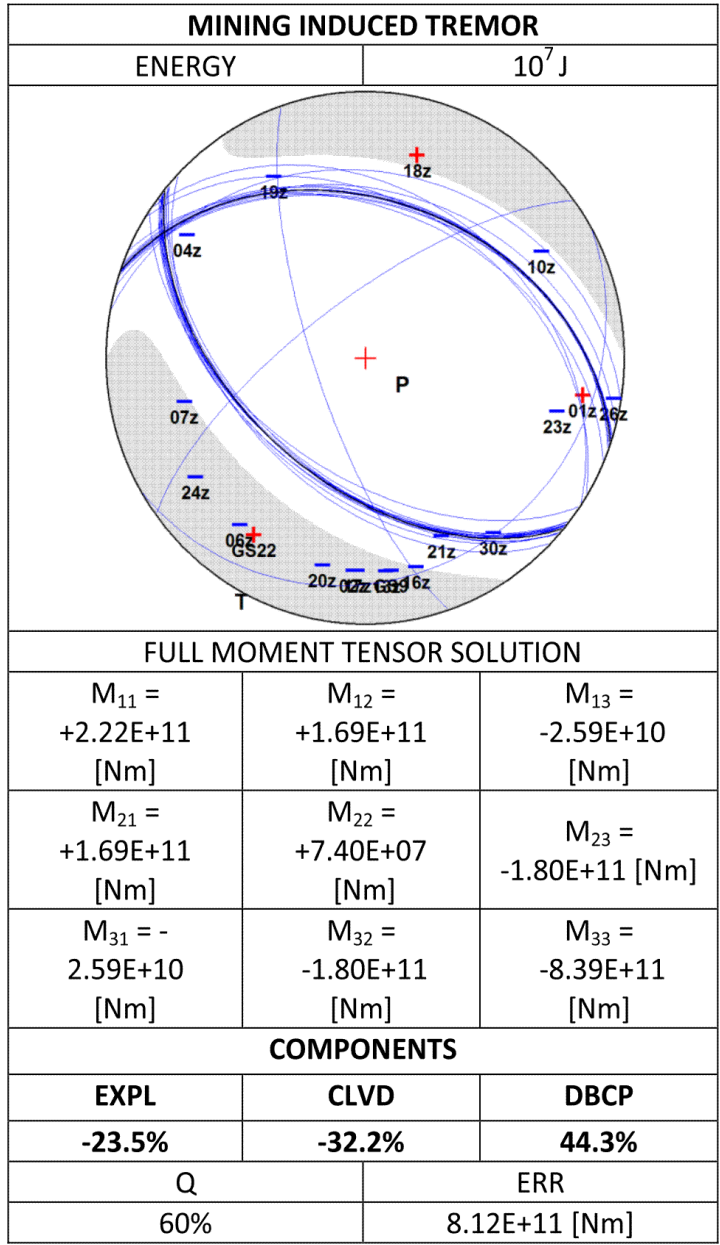

A high value for the DC component may indicate significant shear motion on a discontinuity or on the fault plane of a preexisting fault. The distribution of MT 
component values in this event, especially a high DC component, can be an indicator of "typical" mining induced tremors. Such types of events usually appear spontaneously and can pose a serious threat to miners.

\section{Discussion and conclusions}

Moment Tensor inversion is potentially a very useful tool to determine a point source mechanism. Although in global seismology this approach is commonly used during seismological investigations, in the case of Polish mining seismology it is still not a popular procedure. To obtain reasonable results some factors need to be considered, among other problems with seismic signal recordings described in this paper. MT analysis shows that post-blasting, moderate mining tremors are characterized by very interesting features. Isotropic components of MTs for this group of events, as well as small DC components, could be the main factors differentiating post-blasting seismicity from other spontaneous events. This is also supported by MT of strong-induced tremors. Also worth noting is the growing value of the double couple component followed by an increase in time between detonations and event origins. Increase of the DC component with longer post-blast waiting times can be evidence of stress distribution changes and the elastic rebound of the rock mass We can interpret such kind of events as partially acting on preexisting weak geological zones. Although detonation did not cause immediate tremors, changes in stress fields were strong enough to provoke them some time afterwards. This is a real concern in mine blast prevention. This interpretation is also supported by a decrease in isotropic components of the events, which correspond well to the activation of weak geological zones within the rock mass. We noted that the highest isotropic component was estimated for events provoked with more than $3500 \mathrm{~kg}$ of explosive material. On the other hand, however, for the rest of the provoked events MTs were characterized with similar features. We believe that the amount of explosives did not influence our general conclusions; nevertheless, additional influence of the weight of explosives cannot be excluded. Results presented in this paper show strongly a potential for the use of more sophisticated seismological analyses to confirm that active prevention can reduce seismic risk on mining panels with high rockburst hazard.

\section{Acknowledgements}

The Reviewers are acknowledged for their effort and help in improving the paper. Łukasz Rudziński was partially supported within statutory activities No. 3841/E-41/S/2015 of the Ministry of Sciences and Higher Education of Poland.

\section{References}

Aki K. \& Richards P.G. (1980) Quantitative Seismology - Theory and Methods. Ed. W.H. Freeman \& Co. San Francisco;

Butra J. \& Kudełko J. (2011) Rockburst hazard evaluation and prevention methods in Polish copper mines. Cuprum, 4: 5-20;

Dubiński J. (2013) The mechanisms and consequences of strong mining tremors that occur in Polish hard coal and copper mines. Rock Mechanics for Resources, Energy and Environment - Kwaśniewski \& Łydżba (eds), Taylor \& Francis Group, London, 3138 ;

Gibowicz S. \& Kijko A. (1994) An introduction to mining seismology. Intern. Geophysics Series. 55;

Gogolewska A. \& Bartlewska M. (2004) Rockburst prevention in selected mining panels O/ZG „Polkowice - Sieroszowice” KGHM Polska Miedź SA. during 20012003 (Profilaktyka tąpaniowa w wybranych oddziałach eksploatacyjnych O/ZG „Polkowice - Sieroszowice” KGHM Polska Miedź SA. w latach 2001-2003). Prace 
Naukowe Instytutu Górnictwa Politechniki Wrocławskiej, 106: 55-72 (in Polish);

Gogolewska A. \& Michalak M. (2009) Classifications of roof rockmass and seismic activity in O/ZG „Lubin” (Parametry klasyfikacyjne skał stropowych i aktywność sejsmiczna w O/ZG „Lubin”). Prace Naukowe Instytutu Górnictwa Politechniki Wrocławskiej, 128: 71-102 (in Polish);

Jost M.L. \& Hermann R.B. (1989) A Student's Guide to a Review of Moment Tensor, Seismological Researtch Letters, 60: 37-57;

Koziarz E. \& Szłapka M. (2010) Kierunki dalszego rozwoju informatycznego systemu do bezpośredniej lokalizacji zjawisk dynamicznych w O/ZG „Rudna” KGHM „Polska Miedź” SA. Wiadomości Górnicze, 3:159-174;

Król M., (1998); Application of moment tensor solution and source spectra to tremor source investigation occurred in Polkowice Sieroszowice copper mine. (Zastosowanie tensora momentu sejsmicznego oraz analizy widmowej fali sejsmicznej do badani ognisk wstrząsów $\mathrm{z}$ rejonu kopalni miedzi Polkowice - Sieroszowice). PhD thesis, Institute of Geophysics PAN Warsaw (in Polish) (unpublished); .
Lizurek G., Plasiewicz B. \& Rudziński Ł. (2015) Mining Induced Seismic Event on an Inactive Fault. Acta Geophysica 63, 1: 176200;

Shearer P. (2009) Introduction to seismology, Cambridge University Press, Second edition pp. New York;

Stec K. (2009) Methods for Determining the Mechanism of Tremors Foci (Metody wyznaczania mechanizmu ognisk wstrząsów). Prace Naukowe GIG „Górnictwo i Środowisko”, Katowice, 4,1: 223-236 (in Polish);

Stein S. \& Wysession M. (2003) An introduction to seismology, earthquakes, and earth structure. Blackwell Publishing Ltd, 215 -249;

Talaga A. (2014) Analysis of post blasting source mechanism of mining induced seismic events occured on KWK BobrekCantrum (Bytom). MSc University of Silesia, (in Polish) (unpublished);

Wiejacz P. (1991) Studies on Mechanisms of Mining Tremors with the Use of Seismic Moment Tensor (Badania mechanizmów wstrząsów górniczych przy wykorzystaniu tensora momentu sejsmicznego) Wyd. Instytutu Geofizyki PAN, Warszawa (in Polish). 